\title{
DIFFERENTIAL ANTAGONISM OF ANTIAVOIDANCE, CATALEPTIC AND PTOTIC EFFECTS OF NEUROLEPTICS BY BIPERIDEN
}

\author{
Makoto OKA, Kiyoko YAMADA, Chiaki KAMEI, Kouichi YOSHIDA \\ and Masanao SHIMIZU \\ Department of Pharmacology, Research Laboratories, Dainippon Pharmaceutical Co., Ltd., \\ Suita-shi, Osaka 564, Japan
}

Accepted January 11, 1979

\begin{abstract}
The interaction between neuroleptics and an anticholinergic, biperiden, in the antiavoidance, catalepsy and ptosis tests was investigated in mice for the purpose of predicting the extrapyramidal side-effects of neuroleptics. The cataleptic effect of most neuroleptics used was antagonized to some extent by biperiden, while the ptotic effect was hardly influenced. The antiavoidance effect of neuroleptics was differentially antagonized by biperiden. The antiavoidance effect of haloperidol, trifluperidol and perphenazine was markedly antagonized and that of chlorpromazine moderately. However, the effect of thioridazine, chlorprothixene, levomepromazine and clozapine was little antagonized. In neuropharmacological tests, haloperidol, trifluperidol and perphenazine exhibited a selective antidopaminergic activity, while chlorprothixene, levomepromazine and clozapine showed antidopaminergic, antiadrenergic and also anticholinergic activities when similar doses were given. These results indicate that biperiden antagonism may be marked in the tests related to the extrapyramidal symptoms and in drugs liable to induce extrapyramidal side-effects, however, there would be little or no antagonism in drugs possessing the anticholinergic property and eliciting few extrapyramidal side-effects
\end{abstract}

Extrapyramidal symptoms often arise during psychiatric therapy with neuroleptics. When evaluating new neuroleptics, investigators try to predict the extent of such side-effects as well as the antipsychotic efficacy. The extrapyramidal side-effects have been evaluated by comparing relative effects of each neuroleptic in various pharmacological tests. Among various tests, catalepsy has been regarded as an animal model capable of predicting extrapyramidal symptoms (1-5). Some investigators (5-7) suggested the correlation of rotational or stereotyped behavior with such symptoms. Thus, drugs with weak activities in these tests may be considered as having a low incidence of extrapyramidal side-effects. In addition, Janssen and van Bever (8) proposed that the relative potencies of neuroleptics in the jumping box test and the apomorphine antagonism test might serve as a useful measure of such sideeffects. Although the conclusions derived from these methods often correspond to the virtual incidence of side effects, such is not evident in all cases.

The present study was undertaken to design another method for predicting the potency of extrapyramidal side-effects of neuroleptics. Anticholinergics, which have been used in the therapy of extrapyramidal symptoms, were reported to antagonize differentially various pharmacological effects of the neuroleptic in animal tests $(2,5)$. We attempted to determine whether or not there was any difference also among neuroleptics regarding the degree of 
antagonism produced by the anticholinergic and if such differences reflected the potency of the extrapyramidal side-effects of the drugs. The interaction between eight neuroleptics and an anticholinergic, biperiden, in the antiavoidance, catalepsy and ptosis tests was investigated in mice. The role of neuropharmacological properties of neuroleptics in their interaction with biperiden was also discussed.

\section{MATERIALS AND METHODS}

Subjects: Male STD-ddY strain mice weighing 30-40 $\mathrm{g}$ for the antiavoidance test and 22-26 $\mathrm{g}$ for the other tests were housed in a well-ventilated room at $23-25^{\circ} \mathrm{C}$ and under artificial illumination from $8: 00-18: 00$.

Antiavoidance test: The apparatus and procedure used were as described in a previous paper (9). In short, the mice were trained in a box with two compartments, one darkened and the other not. Each trial was started by placing a mouse in the darkened compartment and then a click sound stimulus was given for $5 \mathrm{sec}$. Unless a mouse moved into the other compartment within $5 \mathrm{sec}$ of the sound stimulus, an electric shock $(5 \mathrm{~mA}, 50 \mathrm{~Hz}, 10 \mathrm{~m} \mathrm{sec})$ was delivered to the feet for $5 \mathrm{sec}$. When the mouse reached the other compartment within the first $5 \mathrm{sec}$, such action was counted as an avoidance response. The mouse was manually returned to the darkened compartment and the next trial was started.

Most of mice acquired the avoidance response for 40-50 trials of training. The animals that showed evidence of the avoidance rate ( $\%$ of avoidance responses in 10 trials) more than $80 \%$ were used for the studies, in groups of 10 . For each treatment, a dose-response curve was constructed and ED50, the dose required to reduce the avoidance rate to $50 \%$ was calculated.

Catalepsy and ptosis tests: At the appropriate time after administration of neuroleptics, a group of 10 mice was tested for catalepsy according to the method of Ueki et al. (10) with modification, and then for ptosis according to the method of Irwin (11).

In the catalepsy test, each mouse was placed with hindpaws on a flat surface and forepaws on a parallel bar $4.5 \mathrm{~cm}$ above the surface. The mice which failed to remove their paws from the bar within $30 \mathrm{sec}$ were considered to be cataleptic. The percentage of cataleptic mice in each group was used to construct the dose-response curve and to calculate the dose which produced catalepsy in $50 \%$ of the mice tested (ED50).

In the ptosis test, the degree of palpebral closure was expressed with scoring (score 0 : completely closed, score 2 : half open eyes, score 4 : wide open eyes, score 1 and 3 : intermediate values). The mean score for each group was used to construct the dose-response curve from which the dose required to reduce the mean score to $50 \%$ (ED50) was calculated.

Anti-apomorphine and anti-noradrenaline tests: The comparative potency of the antidopaminergic and antiadrenergic activities of neuroleptics was determined by the antiapomorphine (12) and anti-noradrenaline (13) tests on a group of 10 mice, respectively.

Injection of apomorphine ( $1 \mathrm{mg} / \mathrm{kg}$ s.c.) to mice elicited continuous verticalization, and such is considered to be associated with the stimulation of dopamine receptors in the neostriatum (12). Then the suppression of this stereotyped behavior was used as an index 
of antidopaminergic activity. At the appropriate time after administration of test drugs, apomorphine was injected s.c. and $20 \mathrm{~min}$ thereafter animals were observed for about $1 \mathrm{~min}$. The degree of verticalization was scored $(0-4)$ for each treatment and the dose required to reduce the mean score to $50 \%$ (ED50) was calculated. Antagonism of the mortality by noradrenaline $(1 \mathrm{mg} / \mathrm{kg}$ i.v.) was used as an index of the antiadrenergic activity. After the same treatment of test drugs as in the anti-apomorphine test, noradrenaline was given i.v. and survival after $24 \mathrm{hr}$ was used as the criterion for the drug effect. The dosage required for $50 \%$ of mice to survive (ED50) was calculated.

Mydriasis and anti-oxotremorine tests: The anticholinergic activity of neuroleptics was determined by the mydriasis and anti-oxotremorine tests (14) on groups of 5 mice, respectively. In the mydriasis test, the pupil size was measured using a stereoscopic microscope. Then, the dose which dilated the pupil size to twice that of the control group (ED $200 \%$ ) was estimated. In the anti-oxotremorine test, mice were injected with oxotremorine $(0.5 \mathrm{mg} / \mathrm{kg}$ i.p. $)$ at the appropriate time after administration of neuroleptics and $15 \mathrm{~min}$ thereafter the degree of tremor induced by oxotremorine was scored (0-3). The dose required to reduce the mean score to $50 \%$ (ED50) was calculated.

Drugs and pretreatment times: Drugs used were chlorpromazine hydrochloride (Wintermine, Shionogi), perphenazine (Triomine, Yamanouchi), thioridazine (Melleril, SandozWander), levomepromazine (Sofmine, Dainippon), chlorprothixene (Chlothixene, Yoshitomi) haloperidol (Serenace, Dainippon), trifluperidol (Triperidol, Yoshitomi), clozapine (Leponex, Sandoz-Wander), biperiden (Akineton, Dainippon), apomorphine hydrochloride, noradrenaline and oxotremorine. In all of the tests, 3-10 dose levels of chlorpromazine, perphenazine, thioridazine, levomepromazine, chlorprothixene, haloperidol, trifluperidol and clozapine were given p.o. at 2, 6, 2, 1, 1, 6, 6 and $1 \mathrm{hr}$ before the tests, respectively. In antiavoidance, catalepsy and ptosis tests, biperiden $10 \mathrm{mg} / \mathrm{kg}$ p.o. (the dose that had little effect in these tests) was given $1 \mathrm{hr}$ before the tests.

All doses were expressed in terms of total salts.

Statistics: Difference between values for individual groups was evaluated using Student's $t$-test or Fisher's exact probability test. ED50 and the $95 \%$ confidence limits were calculated according to the method of Litchfield and Wilcoxon (15). Linear functions fitted by the method of least squares were used to estimate ED200\% and the $95 \%$ confidence limits. Significance of difference between dose-response curves was calculated by parallel line analysis.

\section{RESULTS}

Effects of each neuroleptic in antiavoidance, catalepsy and ptosis tests

Dose-response curves of each neuroleptic, alone, in antiavoidance, catalepsy and ptosis tests are shown in Fig. 1. Neuroleptics such as haloperidol $(0.2$ and $0.5 \mathrm{mg} / \mathrm{kg} \mathrm{p.o.})$, trifluperidol ( 0.2 and $0.5 \mathrm{mg} / \mathrm{kg}$ p.o.), perphenazine $(0.5-2 \mathrm{mg} / \mathrm{kg}$ p.o.), chlorpromazine ( 5 and $10 \mathrm{mg} / \mathrm{kg}$ p.o.), thioridazine (10-50 mg/kg p.o.), chlorprothixene (10-50 mg/kg p.o.), levomepromazine ( 2 and $5 \mathrm{mg} / \mathrm{kg} \mathrm{p.o.)} \mathrm{and} \mathrm{clozapine} \mathrm{(10} \mathrm{and} 20 \mathrm{mg} / \mathrm{kg}$ p.o.) suppressed the active 


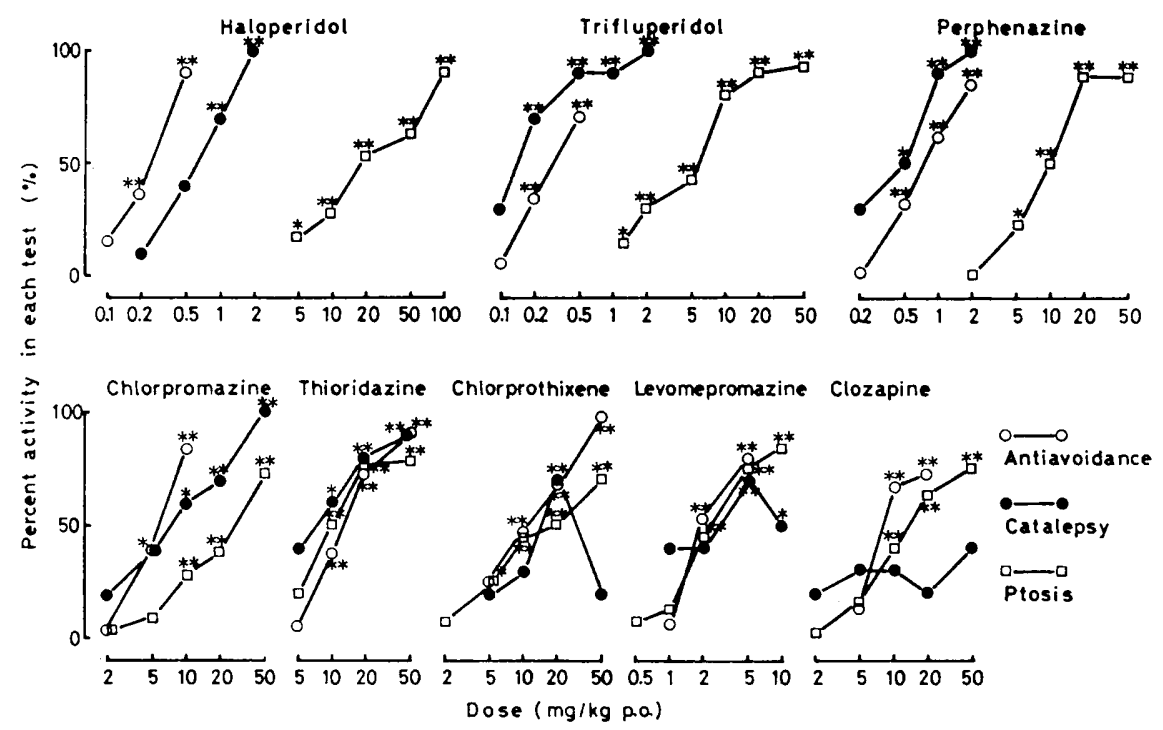

Fig. 1. Comparison of the effects of each neuroleptic in antiavoidance, catalepsy and ptosis tests. Significant difference in comparison with the control group: ${ }^{*} \mathrm{p}<0.05$, $* * \mathrm{p}<0.01$.

avoidance response, dose-relatedly.

Haloperidol, trifluperidol, perphenazine, chlorpromazine and thioridazine induced catalepsy at doses similar to those which suppressed the active avoidance, while chlorprothixene and levomepromazine showed an inverted U-shaped dose-response curve for inducing catalepsy and clozapine induced little catalepsy. The ptotic effect of thioridazine, chlorprothixene, levomepromazine and clozapine was as potent as the antiavoidance effect of these drugs. On the other hand, haloperidol, trifluperidol and perphenazine induced much less and chlorpromazine a slightly less ptotic effect than an antiavoidance effect.

\section{Antagonism of antiavoidance, cataleptic and ptotic effects of neuroleptics by biperiden}

Influence of the anticholinergic, biperiden, on the antiavoidance, cataleptic and ptotic effects of neuroleptics is shown in Figs. 2-4. As shown in Fig. 2, the antiavoidance effect of haloperidol, trifluperidol and perphenazine was markedly reduced by biperiden $10 \mathrm{mg} / \mathrm{kg}$ p.o., and the dose-response curves shifted considerably to the right. The ED50 values of haloperidol, trifluperidol and perphenazine, alone, were $0.23(0.15-0.34), 0.30$ $(0.18-0.50), 0.56(0.38-1.03) \mathrm{mg} / \mathrm{kg}$ p.o., respectively, and such increased to $2.35(1.24-4.48)$, $3.37(1.83-6.21)$ and $7.13(3.97-12.8) \mathrm{mg} / \mathrm{kg}$ p.o. with biperiden. The effect of chlorpromazine was also reduced and the ED50 value was increased from 5.59 (3.75-8.34) to 23.0 (14.3-36.9) $\mathrm{mg} / \mathrm{kg}$ p.o.. However, the effect of thioridazine, chlorprothixene, levomepromazine and clozapine was hardly influenced by biperiden; the ED50 value of each drug, alone, was 13.8 (8.16-23.4), $11.2(5.41-23.0), 2.36(1.47-3.80)$ and 9.68 (6.28-14.9), while that with biperiden was 20.2 (11.7-35.2), $9.05(5.08-16.1), 2.95(1.83-4.77)$ and $14.0(8.26-23.0) \mathrm{mg} / \mathrm{kg}$ p.o., respectively.

The cataleptic effect of most neuroleptics used was reduced to some extent, by biperiden 
$10 \mathrm{mg} / \mathrm{kg}$ p.o. (Fig. 3). The cataleptic effect of haloperidol, trifluperidol, perphenazine and thioridazine was markedly reduced and the dose-response curves were considerably shifted to the right. The ED50 values of haloperidol, trifluperidol, perphenazine and thioridazine, alone, were $0.64(0.38-1.08), 0.14(0.07-0.30), 0.42(0.22-0.80)$ and $4.96(2.25-10.9) \mathrm{mg} / \mathrm{kg}$

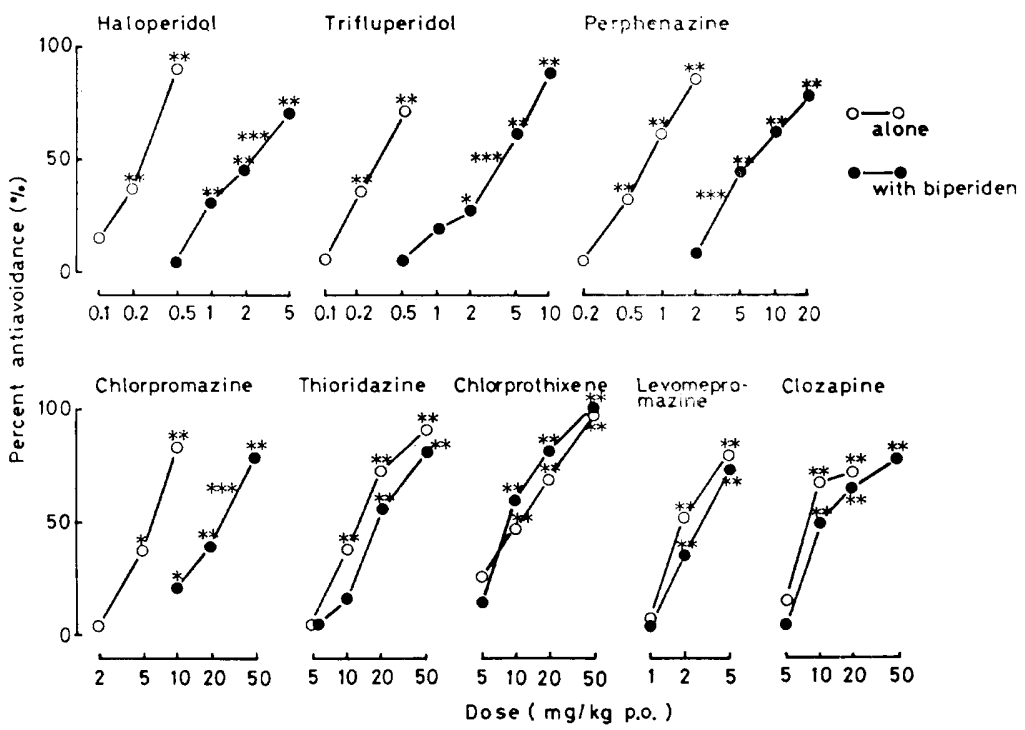

Fig. 2. Antagonism of the antiavoidance effect of neuroleptics by biperiden. Significant difference in comparison with the control group: ${ }^{*} \mathrm{p}<0.05,{ }^{* *} \mathrm{p}<0.01$. Significant difference from the dose-response curve of each neuroleptic, alone: $* * * \mathrm{p}<0.05$.

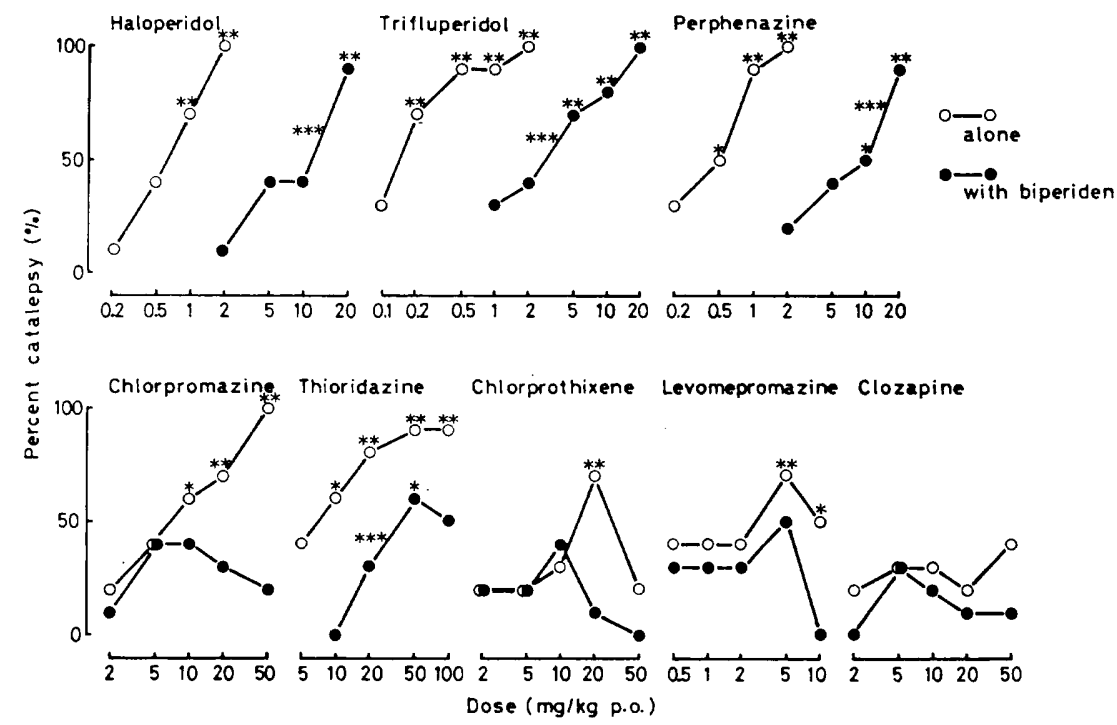

Fig. 3. Antagonism of the cataleptic effect of neuroleptics by biperiden. Significant difference in comparison with the control group: ${ }^{*} p<0.05,{ }^{* *} p<0.01$. Significant difference from the dose-response curve of each neuroleptic, alone: ${ }^{* * *} \mathrm{p}<0.05$. 


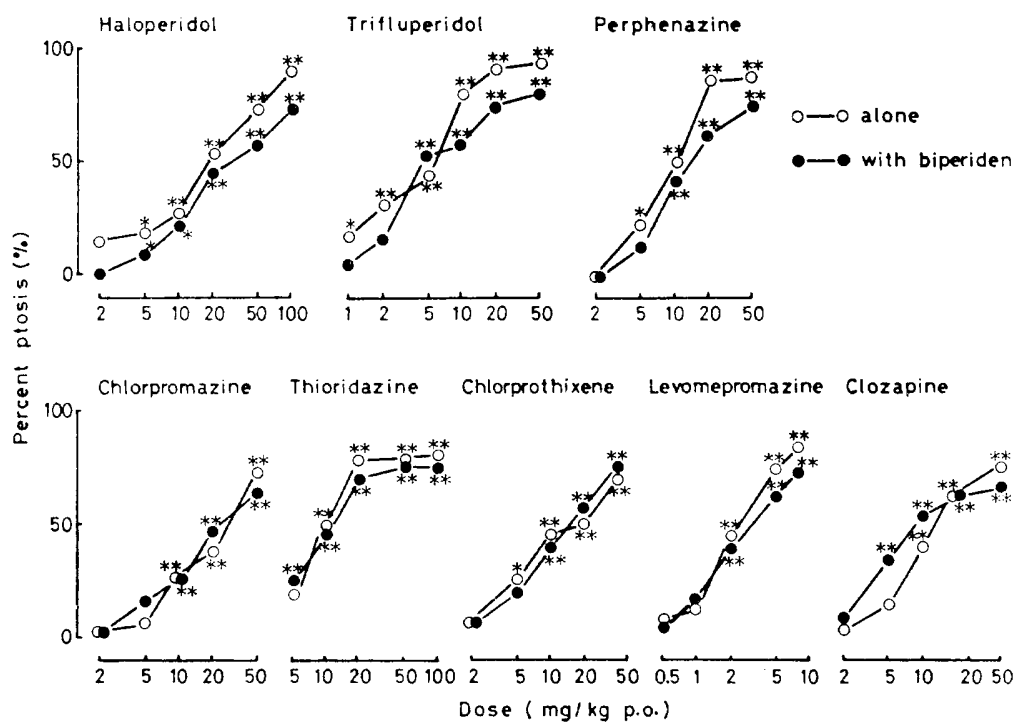

Fig. 4. Antagonism of the ptotic of neuroleptics by biperiden. Significant difference in comparison with the control group: ${ }^{*} \mathrm{p}<0.05,{ }^{* *} \mathrm{p}<0.01$.

p.o., respectively, while those with biperiden were increased to 8.05 (4.68-13.9), 2.66 (1.24 5.73), $5.02(2.26-9.65)$ and $37.0(19.1-71.7) \mathrm{mg} / \mathrm{kg}$ p.o.. The effect of chlorpromazine at higher doses and the effect of chlorprothixene and levomepromazine at some doses were also reduced by biperiden.

The ptotic effect of all neuroleptics tested was little reduced by biperiden $10 \mathrm{mg} / \mathrm{kg}$ p.o. and the dose-response curves changed little (Fig. 4). The ED50 values of haloperidol, trifluperidol, perphenazine, chlorpromazine, thioridazine, chlorprothixene, levomepromazine and clozapine, alone, were 21.2 (11.0-40.9), 4.17 (2.20-7.89), 8.77 (5.66-13.6), 24.9 (12.051.4), 9.89 (6.02-16.3), 17.5 (8.49-36.0), 2.68 (1.45-4.94) and 15.8 (8.49-29.4) $\mathrm{mg} / \mathrm{kg}$ p.o., respectively, while those with biperiden were 32.6 (15.6-68.1), $8.26(3.78-18.0), 16.2$ (8.8829.6), 25.2 (12.4-51.3), 12.5 (6.67-23.5), 15.9 (8.01-31.7), 3.45 (1.84-6.47) and $13.6(5.62-$ 32.8) $\mathrm{mg} / \mathrm{kg}$ p.o.

In these experiments, it was found that there was some difference among tests and also among neuroleptics regarding the degree of antagonism by biperiden.

\section{Neuropharmacological activities of neuroleptics}

Neuropharmacological activities of neuroleptics were examined to attain a better comprehension of the differential antagonism of their effects by biperiden. Effects of neuroleptics in the anti-apomorphine and anti-noradrenaline tests are shown in Table 1; these tests are considered to be appropriate for evaluating antidopaminergic and antiadrenergic activities. Haloperidol, trifluperidol and perphenazine suppressed the verticalization induced by apomorphine ( $1 \mathrm{mg} / \mathrm{kg}$ s.c.) in relatively low doses, but much higher doses were required to protect mice against a lethal dose of noradrenaline ( $1 \mathrm{mg} / \mathrm{kg}$ i.v.). The ratios of anti-noradrenaline to anti-apomorphine effect of haloperidol, trifluperidol 
TABLE 1. Effects of neuroleptics in anti-apomorphine and anti-noradrenaline tests

\begin{tabular}{llcccc}
\hline \multirow{2}{*}{ Drug } & & \multicolumn{2}{c}{ ED50, mg/kg (95\% confidence limits) } & \multirow{2}{*}{ Ratio } \\
\cline { 2 - 4 } & & Anti-apomorphine & Anti-noradrenaline & \\
\hline Haloperidol & p.o. & $0.30(0.20-0.44)$ & $19.1(10.6-34.4)$ & 63.7 \\
Trifluperidol & p.o. & $0.27(0.17-0.42)$ & $15.3(9.64-24.3)$ & 56.7 \\
Perphenazine & p.o. & $0.70(0.44-1.11)$ & $23.6(18.0-31.0)$ & 33.7 \\
Chlorpromazine & p.o. & $6.24(4.53-8.59)$ & $9.91(6.50-15.9)$ & 1.59 \\
Thioridazine & p.o. & $15.5(8.91-26.8)$ & $10.2(7.09-14.6)$ & 0.66 \\
Chlorprothixene & p.o. & $5.69(3.63-8.92)$ & $5.46(3.06-9.86)$ & 0.96 \\
Levomepromazine & p.o. & $4.47(2.48-8.04)$ & $2.25(1.20-4.23)$ & 0.50 \\
Clozapine & p.o. & $31.4(23.0-42.8)$ & $11.5(7.41-17.8)$ & 0.37 \\
Pimozide & p.o. & $0.32(0.20-0.51)$ & $>100$ & $>313$ \\
Spiroperidol & p.o. & $0.30(0.21-0.42)$ & $>100$ & $>333$ \\
Phentolamine & i.p. & $55.7(32.3-95.9)$ & $0.39(0.21-0.71)$ & 0.007 \\
Phenoxybenzamine & i.p. & $30.8(17.4-54.6)$ & $0.08(0.04-0.17)$ & 0.003 \\
\hline
\end{tabular}

TABLE 2. Effects of neuroleptics in mydriasis and anti-oxotremorine tests

\begin{tabular}{lcc}
\hline \multicolumn{1}{c}{ Drug } & $\begin{array}{c}\text { Mydriasis } \\
\text { ED200\%, mg/kg p.o. } \\
(95 \% \text { confidence limits })\end{array}$ & $\begin{array}{c}\text { Anti-oxotremorine } \\
\text { ED 50, mg/kg p.o. } \\
(95 \% \text { confidence limits })\end{array}$ \\
\hline Haloperidol & $>100$ & ca.100 \\
Trifluperidol & $>100$ & $>100$ \\
Perphenazine & $>100$ & ca.100 \\
Chlorpromazine & $>100$ & $29.2(8.97-94.8)$ \\
Thioridazine & $>100$ & $39.5 \quad(18.6-84.0)$ \\
Chlorprothixene & $50.4(23.8-107)$ & $19.3(5.26-42.6)$ \\
Levomepromazine & $49.2(13.7-178)$ & $4.72(1.95-11.4)$ \\
Clozapine & $12.1(5.64-25.9)$ & $21.2(10.6-42.6)$ \\
Biperiden & $4.84(1.76-13.3)$ & $22.2 \quad(10.4-47.6)$ \\
Trihexyphenidyl & $7.75(4.93-12.2)$ & $21.6 \quad(14.5-32.0)$ \\
\hline
\end{tabular}

and perphenazine, as compared by each ED50 value, were 63.7, 56.7 and 33.7, respectively. On the other hand, the anti-apomorphine effects of chlorpromazine, thioridazine, chlorprothixene, levomepromazine and clozapine were seen at almost the same or slightly higher doses as compared with the anti-noradrenaline effect and the ratios of anti-noradrenaline ED50 to anti-apomorphine ED50 of the drugs were nearly 1. It was confirmed that pimozide and spiroperidol (neuroleptics having the property of a typical dopamine blocker) showed a selective anti-apomorphine effect, while phentolamine and phenoxybenzamine ( $\alpha$-blockers) showed a selective anti-noradrenaline effect.

The effects of neuroleptics in the mydriasis and anti-oxotremorine tests were also examined as indexes of the anticholinergic activity and results are shown in Table 2. Among the neuroleptics tested, chlorprothixene, levomepromazine and clozapine induced mydriasis and also suppressed the tremor induced by oxotremorine $(0.5 \mathrm{mg} / \mathrm{kg}$ i.p. $)$. Thioridazine and chlorpromazine had a moderate anti-oxotremorine effect, but failed to induce a mydriatic 
effect. Haloperidol, trifluperidol and perphenazine showed little effect in either test. Biperiden and trihexyphenidyl (anticholinergics) proved to have potent activities in both tests.

In these neuropharmacological tests, a selective antidopaminergic activity was seen in drugs with potent cataleptic and antiavoidance effects which were markedly antagonized by biperiden. On the other hand, drugs in which biperiden antagonism was little or absent, had anticholinergic properties.

\section{DISCUSSION}

The present study was an attempt to predict the extrapyramidal side-effects of neuroleptics by comparing the degree of interaction between an anticholinergic, biperiden, and various neuroleptics. It was found that there was some difference in such interactions, perhaps reflecting the correlation with extrapyramidal side-effects.

There is an extensive literature on the antagonism of the effects of neuroleptics by anticholinergic drugs in various pharmacological tests (1, 2, 5, 6, 16-27). Morpurgo and Theobald (2) reported that anticholinergics, scopolamine and trihexyphenidyl, were capable of reducing the effects of three phenothiazines in such tests as catalepsy, locomotion, amphetamine toxicity, conditioned avoidance and apomorphine-induced stereotypy, whereas in such tests as traction, potentiation of barbiturates, hypothermia and apomorphineinduced vomiting, the antagonistic activity was nil. They concluded that anticholinergics showed a tendency to antagonize selectively the effects related to the extrapyramidal symptoms. Leslie and Maxwell (18) found that benztropine and scopolamine inhibited the anti-amphetamine effect as well as the cataleptic effect of thioproperazine and suggested that the clinical use of these anticholinergics might decrease the psychiatric effectiveness of the neuroleptic because the anti-amphetamine effect might be related to the clinical psychiatric effects.

However, it is dangerous to draw a hasty conclusion from these results with respect to the correlation between pharmacological and clinical effects. Virtually, many components which are related, more or less, to the antipsychotic effects and also to the extrapyramidal side-effects, may be involved in any pharmacological effect of neuroleptics. In addition, the possibility may exist that each neuroleptic exhibits a pharmacological effect through a different mechanism. Certainly, the component related to extrapyramidal symptoms in the pharmacological effects of neuroleptics may be removed by anticholinergics which clinically alleviate such side-effects. If so, the degree of antagonism by the anticholinergic will vary according to the rate that such a component is involved in each pharmacological effect. We assumed when designing this study that the degree of antagonism by the anticholinergic might reflect the correlation between the pharmacological effects of neuroleptics and extrapyramidal symptoms.

In the present study, the anticholinergic, biperiden, was capable of reducing, in most of neuroleptics, the cataleptic effect which was considered to be related to the extrapyramidal symptoms (1-5). The antiavoidance effect of some drugs was also antagonized. However, 
the ptotic effect which was suggested to be related to sedation $(8,28)$ was hardly influenced in any of the drugs tested. These data coincide with the observations of other authors (2, 5) that the degree of antagonism by the anticholinergics varied among pharmacological tests. In addition, the present results showed that there was also a marked difference among neuroleptics regarding the tendency toward antagonism by biperiden. Particularly in the antiavoidance test, biperiden markedly antagonized the effect of haloperidol, trifluperidol and perphenazine which were considered to evoke a relatively high incidence of extrapyramidal symptoms $(29,30)$. The effect of chlorpromazine was antagonized moderately. However, biperiden had little influence on the effects of thioridazine, chlorprothixene, levomepromazine and clozapine which produced less frequently such side effects $(14,29-31)$. Also in the catalepsy test, the effect of haloperidol, trifluperidol and perphenazine was more clearly antagonized by biperiden than that of chlorprothixene, levomepromazine and clozapine. These results show that there may be some difference among tests and also among neuroleptics with regard to the degree of antagonism by biperiden and that such differences may reflect the correlation with extrapyramidal symptoms.

The differential antagonism among tests may be due to differences in the main mechanism involved in each test. Generally, catalepsy is regarded as being associated with blockade of dopamine receptors in the neostriatum $(14,32)$, while ptosis is usually associated with blockade of adrenergic transmission $(3,28)$. It has been hypothesized that a balance exists between dopaminergic and cholinergic mechanisms in the neostriatum (29-31, 33). According to the balance hypothesis, the cataleptic effect of neuroleptics may be exhibited chiefly by the blockade of dopaminergic transmission in the neostriatum and be reduced by biperiden because the balance is restored by diminishing cholinergic influence. On the other hand, the ptotic effect of drugs may not be influenced by biperiden because the effect does not involve the dopaminergic mechanism.

The differential antagonism among neuroleptics seems likely to be due to the difference in their neuropharmacological properties. Haloperidol, trifluperidol and perphenazine selectively suppressed the apomorphine-induced verticalization attributed to actions on the neostriatum (12), yet had fewer antiadrenergic and anticholinergic activities. Therefore, the effects of these drugs may be clearly antagonized by biperiden because these drugs have a relatively potent activity on the neostriatum. On the other hand, as shown in both mydriasis and anti-oxotremorine tests, chlorprothixene, levomepromazine and clozapine exhibited considerable anticholinergic activity in addition to antidopaminergic and antiadrenergic activities. Thus, the effects of these drugs may not be further antagonized by biperiden because of their own built-in anticholinergic property.

It is generally considered that anticholinergics clinically attenuated the extrapyramidal side-effects of neuroleptics while modifying to a lesser extent the antipsychotic activity. However, Singh and Smith (34) and Singh and Kay (35) recently observed that the anticholinergic, benztropine, reduced the therapeutic effects of chlorpromazine and haloperidol in terms of social, affective and cognitive dysfunctions while hallucinatory behavior and disturbed attention were not so affected. In analogy with their clinical data, the possibility 
exists that biperiden may also partly antagonize the component related to the therapeutic effects in the animal experiments employed herein.

The present results indicate that marked antagonism by biperiden may be seen in tests related to extrapyramidal symptoms and also in neuroleptics that are relatively liable to induce the extrapyramidal side-effects. The effects of drugs that have the anticholinergic property in themselves and elicit few extrapyramidal side-effects may be antagonized little or not at all antagonized by biperiden. Such differences among neuroleptics regarding biperiden antagonism may aid in predicting the potency of extrapyramidal side-effects by drugs.

\section{REFERENCES}

1) Morpurgo, C.: Effects of antiparkinson drugs of a phenothiazine-induced catatonic reaction. Archs int. Pharmacodyn. Thér. 137, 84-90 (1962)

2) Morpurgo, C. and Theobald, W.: Influence of antiparkinson drugs and amphetamine on some pharmacological effects of phenothiazine derivatives used as neuroleptics. Psychopharmacologia 6, 178-191 (1964)

3) Van Rossum, J.M., Janssen, P.A.J., Boissier, J.R., Julou, L., Loew, D.M., Nielsen, I.M., Munkvad, I., Randrup, A., Stille, G. and Tedeschi, D.H.: The neuroleptics. Mod. Probl. Pharmacopsychiat., Edited by BoBon, D.P., JANSSEN, P.A.J. AND BoBon, J., Vol. 5, p. 23-70, Liège, Karger, München, Paris and New York (1970)

4) Hornykievicz, O.: Parkinsonism induced by dopaminergic antagonists. Adv. Neurol., Edited by Calne, D.B., Chase, T.N. and Barbeau, A., Vol. 9, p. 155-164, Raven Press, New York (1975)

5) Setler, P., Sarau, H. and McKenzie, G.: Differential attenuation of some effects of haloperidol in rats given scopolamine. Europ. J. Pharmacol. 39, 117-126 (1976)

6) Kelly, P.H. AND Miller, R.J.: The interaction of neuroleptic and muscarinic agents with central dopaminergic systems. Brit. J. Pharmacol. 54, 115-121 (1975)

7) Hill, R.T. and Tedeschi, D.H.: Animal testing and screening procedures in evaluating psychotropic drugs. An Introduction to Psychopharmacology, Edited by RECH, R.H. AND Moore, K.E., p. 237-288, Raven Press, New York (1971)

8) Janssen, P.A.J. AND VAN Bever, W.F.M.: Advances in the search for improved neuroleptic drugs. Current Development in Psychopharmacology, Edited by Essman, W.B. AND Valzelli, L., Vol. 2, p. 167-184, Spectrum Publ. Inc., New York, Toronto, London and Sydney (1975)

9) OKa, M. AND Shimizu, M.: A simple avoidance procedure for testing psychotropic drugs in mice. Japan. J. Pharmacol. 25, 121-127 (1975)

10) Ueki, S., Fujiwara, M., Inoue, K., Kataoka, Y., Ibil, N. and Wada, Y.: Behavioral pharmacology of maprotyline, a new antidepressant. Folia pharmacol. japon. 71, 789-815 (1975) (Abs. in English)

11) IRwiN, S.: Comprehensive observational assessment: Ia. a systematic, quantitative procedure for assessing the behavioral and physiologic state of the mouse. Psychopharmacologia 13, 222-257 (1968)

12) Protais, P., Costentin, J. And Schwartz, J.C.: Climbing behavior induced by apomorphine in mice: a simple test for the study of dopamine receptors in striatum. Psychopharmacology 50, 1-6 (1976)

13) Janssen, P.A.J., Niemegeers C.J.E. and Schellekens, K.H.L.: Is it possible to predict the clinical effects of neuroleptic drugs (major tranquilizers) from animal data? Part 1: "neuroleptic activity spectra" for rats. Arzneim.-Forsch. 15, 104-117 (1965)

14) Stille, G., Lauener, H. and Eichenberger, E.: The pharmacology of 8-chloro-11-(4methyl-1-piperazinyl)-5H-dibenzo[b,e] [1,4] diazepine (clozapine). Il Farmaco 26, 603-625 (1971)

15) Litchfield, J., JR. AND Witcoxon, F.: A simplified method of evaluating dose-effect 
experiments. J. Pharmacol. exp. Ther. 96, 99-113 (1949)

16) Hanson, H.M., Stone, C.A. and Witoslawski, J.J.: Antagonism of the antiavoidance effects of various agents by anticholinergic drugs. J. Pharmacol. exp. Ther. 173, 117-124 (1970)

17) Fibiger, H.C., Zis, A.P. AND Phillips, A.G.: Haloperidol-induced disruption of conditioned avoidance responding: attenuation by prior training or by anticholinergic drugs. Europ. J. Pharmacol. 30, 309-314 (1975)

18) Leslie, G.B. AND Maxwell, D.R.: Some pharmacological properties of thioproperazine and their modification by anti-parkinsonian drugs. Brit. J. Pharmacol. 22, 301-317 (1964)

19) Muller, P. and Seeman, P.: Neuroleptics: relation between cataleptic and anti-turning actions, and role of the cholinergic system. J. Pharm. Pharmacol. 26, 981-984 (1974)

20) Sayers, A.C., Bürki, H.R., Ruch, W. and Asper, H.: Anticholinergic properties of antipsychotic drugs and their relation to extrapyramidal side-effects. Psychopharmacology 51, 15-22 (1976)

21) OLDS, M.E.: Alterations by centrally acting drugs of the suppression of self-stimulation behavior in the rat by tetrabenazine, physostigmine, chlorpromazine and phenobarbital. Psychopharmacologia 25, 299-314 (1972)

22) Wauquier, A., Niemegeers, C.J.E. and Lal, H.: Differential antagonism by the anticholinergic dexetimide of inhibitory effects of haloperidol and fentanyl on brain self-stimulation. Psychopharmacologia 41, 229-235 (1975)

23) ANDÉn, N.-E.: Dopamine turnover in the corpus striatum and the limbic system after treatment with neuroleptic and anti-acetylcholine drugs. J. Pharm. Pharmacol. 24, 905-906 (1972)

24) O'Keeffe, R., Sharman, D.F. and Vogt, M.: Effect of drugs used in psychoses on cerebral dopamine metabolism. Brit. J. Pharmacol. 38, 287-304 (1970)

25) Bowers, M.B., JR. AND Roth, R.H.: Interaction of atropine-like drugs with dopaminecontaining neurones in rat brain. Brit. J. Pharmacol. 44, 301-306 (1972)

26) Corrodi, H., FuXf, K. ANd Lidbrink, P.: Interaction between cholinergic and catecholaminergic neurones in rat brain. Brain Res. 43, 397-416 (1972)

27) Bartholini, G., Keller, H.H. and Pletscher, A.: Drug-induced changes of dopamine turnover in striatum and limbic system of the rat. J. Pharm. Pharmacol. 27, 439-442 (1975)

28) Tedeschi, D.H.: Criteria for the selection of pharmacological test procedures useful in the evaluation of neuroleptic drugs. The Present Status of Psychotropic Drugs, Edited by Cerletti, A. And Bove, F.J., p. 145-153, Excepta Medica Foundation, Amsterdam (1969)

29) Snyder, S., Greenberg, D. and Yamamura, H.I.: Antischizophrenic drugs and brain cholinergic receptors-Affinity for muscarinic sites predicts extrapyramidal effects. Arch. gen. Psychiat. 31, 58-61 (1974)

30) Stimmel, G.L.: Neuroleptics and the corpus striatum: clinical implications. Dis. Nerv. Sys. 37, 219-224 (1976)

31) Miller, R.J. AND Hiley, C.R.: Anti-muscarinic properties of neuroleptics and druginduced Parkinsonism. Nature 248, 596-597 (1974)

32) Koffer, K.B., Berney, S. and Hornykievicz, O.: The role of the corpus striatum in neuroleptic- and narcotic-induced catalepsy. Europ. J. Pharmacol. 47, 81-86 (1978)

33) Klawans, H.L., Jr.: The pharmacology of parkinsonism. Dis. Nerv. Sys. 29, 805-816 (1968)

34) Singh, M.M. ANd Smith, J.M.: Reversal of some therapeutic effects of an antipsychotic agent by an antiparkinsonism drug. J. Nerv. Ment. Dis. 157, 50-58 (1973)

35) Singh, M.M. AND KAY, S.R.: Therapeutic reversal with benztropine in schizophrenicsPractical and theoretical significance. J. Nerv. Ment. Dis. 160, 258-266 (1975) 